\title{
Re-Treatment Decisions for Failed Posterior Restorations among Dentists in Kuwait
}

\author{
Qasem Alomari ${ }^{\mathrm{a}}$ \\ Bader Al-Kanderia \\ Muawia Qudeimat ${ }^{\mathrm{b}}$ \\ Ridwaan Omara
}

\begin{abstract}
Objectives: To compare re-treatment choices for MOD amalgam or resin composite restorations with or without cusp fracture among dentists in Kuwait.

Methods: A random sample of 158 dentists completed a questionnaire designed to obtain sociodemographic, educational and work-related information and their choices for re-treatment of four scenarios of failed restorations on lower first molars: 1. MOD amalgam restoration; 2. MOD composite restoration; 3. MOD amalgam restoration with cuspal fracture; 4. MOD composite restoration with cuspal fracture. Re-treatment options were: re-treating with amalgam; re-treating with composite; placing an onlay; or, placing a crown. For the purpose of analysis, responses were dichotomized into re-treatment with a direct or indirect restoration.

Results: For cases 1 and 2, most participants chose to re-treat with amalgam restoration and for cases 3 and 4, most chose to place an indirect restoration. In general, an increased tendency towards the indirect option was associated with increased age, being a male and being a specialist. Tendencies to place an indirect restoration did not differ between cases 1 and $2(P=1.0)$ or cases 3 and 4 $(P=0.317)$, although the tendency to do so was significantly greater in case 3 than $1(P=0.000)$ and case 4 than $2(P=0.000)$.

Conclusions: The variation noted among dentists regarding their stated choices for re-treating failed posterior restorations appeared to be associated with gender, education and experience factors. A tendency towards indirect restorations was seen when the restoration is associated with a fractured cusp. (Eur J Dent 2010;4:41-49)
\end{abstract}

Key words: Re-treatment; Amalgam; Resin composite; Decision making.

- a Department of Restorative Sciences, Faculty of Dentistry, Kuwait University, Kuwait.

b Department of Developmental and Preventive Sciences, Faculty of Dentistry, Kuwait University, Kuwait.

- Corresponding author: Dr Qasem Alomari, Department of Restorative Sciences, Faculty of Dentistry, Kuwait University, P. O. Box 24923 Safat, 13110, Kuwait. Phone: +9654986652

Fax: +9655326049

E-mail: qalomaridahsc.edu.kw

\section{INTRODUCTION}

Re-treatment and/or replacement of failed restorations have been shown to constitute as much as fifty percent of the volume of restorative work performed. ${ }^{1-4}$ Variations associated with the decisions that dentists make regarding such procedures have also been found to be large. ${ }^{5,6}$ Increasingly there is a realization that the way in which dental practice is commonly undertaken 
can be improved, and if there is to be less of the apparent subjectivity affecting the process of decision making, then the mechanisms underlying diagnostic thinking should be better understood. ${ }^{7,8}$

In making treatment decisions, dentists have to take into consideration all the treatment alternatives and materials available, besides several other patient- and dentist-related factors. ${ }^{5}$ Amalgam has for long been the predominant direct restorative material for posterior teeth. More recently, resin composite materials are increasingly being used for placement and replacement of restorations. ${ }^{9}$ To date, no clear guidelines have been established on the criteria that clinicians should use when considering the replacement of a restoration, or, for that matter, what material(s) ought to be used.

A common clinical scenario that dentists are faced with is a restored tooth which is questionable on account of frank or suspected recurrent caries and/or associated tooth or restoration fracture, or both. In this regard, the prevalence of bulk restoration fracture or cusp fracture has been found to be at least $20 \%$ among patients, and is an important consideration when evaluating tooth status prior to prescribing the appropriate re-treatment: the clinician's assessment of the likelihood that the tooth will remain intact and withstand normal function will determine the need to protect it with an indirect restoration or not. ${ }^{10,11}$ Although several studies have evaluated the clinical performance of large direct and indirect restorations, there is uncertainty about which procedure provides the best long-term outcome for a structurally compromised tooth. ${ }^{12,13}$

The factors that influence decision making in dentistry have been classified as dentist-, practice- and patient-related. ${ }^{14}$ Dentist factors include age, experience, skills, knowledge, and treatment preferences. ${ }^{15}$ Differences in dentists' educational background and differing levels of work experience are also influential in the process. ${ }^{14-16}$ Practice-related factors include type, location, and size of practice, while patient-related factors include oral hygiene, diet, fluoride exposure, insurance, preferences, medications and diseases. ${ }^{17}$ As an example, cost of treatment was found to be more dominant than oral health status and patient preference in influencing treatment choice. ${ }^{18}$

The aims of this study were to evaluate den- tists' stated re-treatment choices for simulated cases of amalgam or resin composite restorations that needed replacement due to recurrent caries, and had or did not have cuspal fracture. The hypothesis tested was that participants' tendency to place a particular material, or an indirect restoration in such situations is independent of their education, work experience and other demographic factors.

\section{MATERIALS AND METHODS}

A sample of 158 dentists, randomly drawn from the membership of the Kuwait Dental Association, and designed to proportionally represent all of the six governorates of Kuwait, agreed to participate in the study. The total number of practicing dentists in Kuwait is 1160 . Among them 826 practicing in the government sector while 334 practicing in the private sector. The study was carried out by means of a structured, self-administered questionnaire that had been pre-tested by five dentists who were mainly engaged in clinical practice, and revised as necessary (these individuals were not included in the study). Along with questionnaire, four sets of typodonts (Frasaco ${ }^{\circledR} \mathrm{GmbH}$, Tettnang, Germanyl that had been modified to simulate restorations with various degrees of failure were available for participants to examine.

Participants were met in person by one of the investigators (BA-K) at a pre-arranged time, who, after explaining the nature and aim of the study, handed them the anonymous questionnaire together with assurances about confidentiality of identity. None of the approached dentists refused to participate in the study. In addition to age and gender, the questionnaire inquired about respondents' educational background (country of undergraduate education and dental specialty), and practice characteristics (private/government sector and location of practice). A clinical scenario with four variations on failed restorations, each represented by its own pre-restored typodont, was then sequentially presented to the participant. They were asked to choose their treatment of choice from a list of given options, without any economic constraints: replacement of the restoration with amalgam, replacement of the restoration with resin composite, restoration with an indirect onlay, or re-restoration followed by crowning of the tooth. An assurance was given 
that there were no "right" or "wrong" answers that were being sought or monitored. Each of the four scenarios was accompanied by the following patient information: "A 45-year-old patient, who is in good general health and has a complete dentition except for third molars, attends for examination. This is your first examination of the patient. There are no clinical symptoms from the teeth or oral tissues. Besides the tooth in question, there are no other dental problems and no other dental treatment is being planned. The occlusion of the patient is normal and all of his teeth are vital." The tooth in question was sequentially one of the following, and was thus graphically depicted on the typodont:

Case \#1: There is a 5 year-old MOD amalgam restoration present in the lower first molar. The restoration is discolored and has recurrent caries all around its margins.

Case \#2: As for \#1, but the restoration was of resin composite.

Case \#3: As for \#1, but the lingual cusps of the involved tooth were fractured $3 \mathrm{~mm}$ supragingivally.

Case \#4: As for \#3, but the restoration was of resin composite.

After data collection, results were analyzed using SPSS version 15.0 (SPSS, Chicago, IL, USA). Descriptive statistics were calculated for all the study variables. Statistical significance of differences between the groups compared was evaluated by means of the chi-square test. In addition, after dichotomizing the treatment alternatives for all cases into: a) re-treatment with direct restoration or b) re-treatment with indirect restoration, a logistic regression model was fitted to the data and corresponding odd ratios calculated. For all categorical variables, dummy variables were calculated in the model. Model fit was assessed by classification plots, outlier analysis, improvement of the 2 log likelihood (2LL) statistic, and by residual plots. Wilcoxon Signed Rank test was used to compare the choices for re-treatment between the two restorative materials, and between choices for fractured and non-fractured teeth for a given restorative material.

\section{RESULTS}

The distribution of re-treatment choices showed that, for Case \#1, most participants would replace the failed amalgam restoration with a new one, and only a few would opt for a resin composite restoration or an indirect restoration. In contrast, for Case \#2, the majority of participants preferred to replace the failed resin composite restoration with a new amalgam restoration, with only $22 \%$ choosing to replace with a new composite restoration. For Cases \#3 and \#4, large majorities of participants chose to place an indirect restoration (crown or, to a lesser extent, onlay) after first restoring the MOD portion with amalgam or resin composite (Table 1).

Characteristics of participants who chose to restore the tooth in case \#1 and \#3 with either direct or indirect restoration are presented in Table 2. The regression analysis showed that dentist factors were variously associated with the treatment choices they made (Table 3). For Case \#1, middle-aged dentists were less inclined to place indirect restorations than older dentists $(P=0.001$, OR 0.388), as were dentists from the Middle East compared to dentists from Asia $(P=0.019$, OR 0.391). For Case \#3, male dentists, older dentists and dentists working in the government sector each had a greater tendency to place indirect restorations.

Table 4 shows the characteristics of participants who chose to restore the tooth in case \#2 and \#4 with either direct or indirect restoration. For Case \#2, the regression analysis showed that general practitioners had less tendency to place indirect restorations compared to prosthodontists and other specialists ( $P=0.019$, OR 0.444) (Table 3). Furthermore, middle age dentists had less tendency to place indirect restorations compared to older dentists ( $P=0.000,0 R$ 0.332). Again, dentists from the Middle East had less tendency for indirect restorations compared to those from Asia ( $P=0.022$, OR 0.404).

For Case \#4, the regression analysis showed that being a male dentist and working for the government were the two factor associated with dentists tendencies to place indirect restorations $(P=0.018,0 R 2.953$ and $P=0.016,0 R 4.701$, respectively).

Wilcoxon Signed Rank test showed no statistical difference in dentists' tendency to place an indirect restoration in Case \#1 compared to Case \#2 $(P=1.0)$, or in Case \#3 compared to Case \#4 $(P=0.317)$. However, the tendency to do so was 
significant when comparing Cases \#1 and \#3 $(\mathrm{P}=0.000)$ and Cases \#2 and \#4 (P=0.000).

\section{DISCUSSION}

Because the replacement of failed restorations comprises a large proportion of all restorations placed for adult patients, ${ }^{9,18}$ the importance of appropriate decisions being made during the re-treatment process in order to limit the 'repeatrestoration' cycle ${ }^{5}$ is clear. An understanding of the disease process and knowledge of the available treatment options is an insufficient basis for any clinical decision making. ${ }^{19}$ The prognosis for alternative treatments, and in the context of the present study, specifically the choice between crown therapy and a direct restoration, is also an important factor. ${ }^{20}$

Table 1. Distribution of re-treatment choices (\%) made by participants for the different cases (\#1 MOD amalgam restoration; \#2 MOD composite restoration; \#3 MOD amalgam restoration with cuspal fracture; \#4 MOD composite restoration with cuspal fracture).

\begin{tabular}{lcccccc}
\hline Choice & $\# 1$ & $\# 2$ & $\# 3$ & $\# 4$ & Total \\
\hline Re-treatment with amalgam & $113(72)$ & $99(63)$ & $22(14)$ & $19(12)$ & $253(40)$ \\
Re-treatment with resin composite & $21(13)$ & $35(22)$ & $7(4)$ & $12(8)$ & $75(12)$ \\
Re-treatment with onlay & $13(8)$ & $14(9)$ & $33(21)$ & $35(22)$ & $95(15)$ \\
Re-treatment with crown & $11(7)$ & $10(6)$ & $96(61)$ & $92(58)$ & $209(33)$ \\
\hline
\end{tabular}

Table 2. Distribution of dichotomized re-treatment choices (\%) for cases \#1 (MOD amalgam restoration) and \#3 (MOD amalgam restoration with cuspal fracture) according to different independent variables.

\begin{tabular}{|c|c|c|c|c|c|}
\hline \multirow[b]{2}{*}{ Independent Variables } & \multirow[b]{2}{*}{ Total $(\%)$} & \multicolumn{2}{|c|}{ Case 1} & \multicolumn{2}{|c|}{ Case 3} \\
\hline & & Direct $(\%)$ & Indirect $(\%)$ & Direct $(\%)$ & Indirect $(\%)$ \\
\hline \multicolumn{6}{|l|}{ Gender } \\
\hline Male & $111(70)$ & 92 (83) & 19 (17) & 15 (13.5) & 96 (86.5) \\
\hline Female & 47 (30) & 42 (89) & $5(11)$ & $14(30)$ & $33(70)$ \\
\hline \multicolumn{6}{|l|}{ Age (yrs) } \\
\hline$\leq 35$ & 63 (40) & $53(84)$ & $10(16)$ & $11(17.5)$ & 52 (82.5) \\
\hline $36-49$ & 79 (50) & 69 (87) & $10(13)$ & $16(20)$ & $63(80)$ \\
\hline$\geq 50$ & $16(10)$ & $12(75)$ & 4 (25) & 2 (12.5) & 14 (87.5) \\
\hline \multicolumn{6}{|l|}{ Education } \\
\hline USA & $20(13)$ & $18(90)$ & $2(10)$ & $4 \quad(20)$ & $16(80)$ \\
\hline Western Europe & $9 \quad 16)$ & $7 \quad(78)$ & $2(22)$ & $2(22)$ & $7 \quad(78)$ \\
\hline Eastern Europe & 27 (17) & 21 (78) & $6(22)$ & 4 (15) & $23(85)$ \\
\hline Middle East & $70 \quad(44)$ & 61 (87) & $9(13)$ & $16(23)$ & $54(77)$ \\
\hline Asia & 32 (20) & $27(84)$ & $5(16)$ & 3191 & 29 (91) \\
\hline \multicolumn{6}{|l|}{ Specialty } \\
\hline GP & 99 (63) & $86(87)$ & $13(13)$ & $22(22)$ & 77 (78) \\
\hline Prosthodontics & $31 \quad(20)$ & $25(81)$ & 6 (19) & $5(16)$ & $26(84)$ \\
\hline Other Specialists & 28 (17) & $23(82)$ & $5 \quad(18)$ & $2(7)$ & $26(93)$ \\
\hline \multicolumn{6}{|l|}{ Workplace } \\
\hline Government & 125 (79) & $105(84)$ & $20(16)$ & $21(17)$ & 104 (83) \\
\hline Private & $33 \quad(21)$ & 29 (88) & 4 (12) & $8 \quad(24)$ & $25 \quad(76)$ \\
\hline \multicolumn{6}{|l|}{ Area of Practice } \\
\hline Suburban & $51 \quad$ (32) & 45 (88) & $6 \quad(12)$ & $4(8)$ & 47 (92) \\
\hline Urban & 107 (68) & 89 (83) & $18(17)$ & 25 (23) & 82 (77) \\
\hline
\end{tabular}


The 'paper patient case' technique, as used in our study, has been found to be feasible and useful in studies on clinical decision making. ${ }^{21}$ While the exclusion of a patient means that the observer cannot pick up potentially important cues from a 'live' situation, it has the advantage of controlling precisely those 'live' background variables, even if some 'artificiality' is thus introduced. What neither of these approaches can avoid, however, is the likelihood that what people say they do in a situation and what they actually do can be quite different. ${ }^{22,23}$ Clearly, this study has neither addressed nor clarified this last point. However, it can be noted that cost of treatment is a major consideration

Table 3. Dentist factors which were significantly associated with preference for an indirect restorative technique for the different cases (\#1 MOD amalgam restoration; \#2 MOD composite restoration; \#3 MOD amalgam restoration with cuspal fracture; \#4 MOD composite restoration with cuspal fracture).

\begin{tabular}{|c|c|c|c|c|c|c|}
\hline Case & \multicolumn{2}{|c|}{ Dentist factors } & Estimate & P-value & OR & $95 \% \mathrm{Cl}$ \\
\hline \multirow{8}{*}{ \#1 } & \multirow{3}{*}{ Age (yrs) } & $\leq 35$ & -0.374 & ns & ns & $0.346-1.370$ \\
\hline & & $36-49$ & -0.946 & 0.001 & 0.388 & $0.220-0.684$ \\
\hline & & $\geq 50 *$ & - & - & - & - \\
\hline & \multirow{5}{*}{ Education } & USA & -0.431 & ns & 0.650 & $0.187-2.263$ \\
\hline & & Western Europe & 0.940 & ns & 2.561 & $0.778-8.430$ \\
\hline & & Eastern Europe & 1.089 & ns & 2.970 & $0.571-15.449$ \\
\hline & & Middle East & -0.940 & 0.019 & 0.391 & $0.179-0.855$ \\
\hline & & Asia* & - & - & - & - \\
\hline \multirow{8}{*}{ \#2 } & \multirow{3}{*}{ Age (yrs) } & $\leq 35$ & -0.166 & ns & 0.847 & $0.425-1.688$ \\
\hline & & $36-49$ & -1.103 & 0.000 & 0.332 & $0.184-0.598$ \\
\hline & & $\geq 50 *$ & - & - & - & - \\
\hline & \multirow{5}{*}{ Education } & USA & -0.193 & ns & 0.825 & $0.246-2.768$ \\
\hline & & Western Europe & 0.997 & ns & 2.710 & $0.818-8.973$ \\
\hline & & Eastern Europe & 0.645 & ns & 1.906 & $0.389-9.338$ \\
\hline & & Middle East & -0.907 & 0.022 & 0.404 & $0.186-0.877$ \\
\hline & & Asia* & - & - & - & - \\
\hline \multirow{11}{*}{ \#3 } & \multirow{3}{*}{ Specialty } & GP & -0.812 & 0.019 & 0.444 & $0.226-0.873$ \\
\hline & & Prosthodontics & -0.156 & ns & 0.856 & $0.380-1.927$ \\
\hline & & Other Specialists* & - & - & - & - \\
\hline & \multirow{2}{*}{ Gender } & Male & 0.867 & 0.000 & 2.380 & $1.512-3.746$ \\
\hline & & Female* & - & - & - & - \\
\hline & & & & & & \\
\hline & \multirow{3}{*}{ Age (yrs) } & $\leq 35^{*}$ & - & - & - & - \\
\hline & & $36-49$ & 0.334 & 0.219 & 1.397 & $0.820-2.381$ \\
\hline & & $\geq 50^{*}$ & 0.862 & 0.022 & 2.369 & $1.131-4.964$ \\
\hline & Worknlace & Government & 0.778 & 0.009 & 2.176 & $1.215-3.897$ \\
\hline & vruinplace & Private* & - & - & - & - \\
\hline \multirow{4}{*}{ \#4 } & \multirow{2}{*}{ Gender } & Male & 1.083 & 0.018 & 2.953 & $1.204-7.241$ \\
\hline & & Female* & - & - & - & - \\
\hline & \multirow{2}{*}{ Workplace } & Government & 1.548 & 0.016 & 4.701 & $1.329-16.620$ \\
\hline & & Private* & - & - & - & - \\
\hline
\end{tabular}

*: Reference in logistic regression models fitted to the data separately for each case. 
in situations where significantly cheaper alternatives exist. ${ }^{24}$ In Kuwait, dental treatment is provided free in the Ministry of Health, so that economic constraints would not have been a serious factor for many of the dentists participating in the study. Equally, those dentists in the private sector are unlikely to encounter patients with limited financial means, so that treatment options were made free of such constraints might be considered valid.

The choice of the mandibular first molar typodont as the basis for comparison was made for two reasons: firstly, for standardization of the four scenarios, and secondly because previous research has found the mandibular first molar to be the posterior tooth to be most affected with cuspal fracture, and furthermore that lingual cusps were affected twice as much as facial cusps. ${ }^{25,26}$

Our results show that there was widespread variation among the various dentist groups re- garding the choice of re-treatment for all cases of failed restorations. This general inconsistency in preferred treatment is in agreement with patterns observed among dentists in the factors they regarded as important in deciding on treatments in restorative dentistry, ${ }^{8,27}$ endodontics, ${ }^{28}$ oral surgery $^{29}$ and simulated prosthodontic scenarios. ${ }^{20,21,30}$ In previous research on re-treatment of failed three-surface amalgam restorations, indirect restoration was the option of choice. ${ }^{31}$ Private sector dentists and dental educators chose this option more frequently than others. In our study, the majority of participants chose to re-treat failed three-surface amalgam or resin composite restorations with a new amalgam restoration. The difference in the results might be due to differences in size of the failed restoration in the two studies. The results of our study also showed that the majority of dentists in Kuwait still believe in amal-

Table 4. Distribution of dichotomized re-treatment choices (\%) for cases \#2 (MOD composite restoration) and \#4 (MOD composite restoration with cuspal fracture) according to different independent variables.

\begin{tabular}{|c|c|c|c|c|c|}
\hline \multirow[b]{2}{*}{ Independent Variables } & \multirow[b]{2}{*}{ Total $(\%)$} & \multicolumn{2}{|c|}{ Case 2} & \multicolumn{2}{|c|}{ Case 4} \\
\hline & & Direct $(\%)$ & Indirect (\%) & Direct $(\%)$ & Indirect (\%) \\
\hline \multicolumn{6}{|l|}{ Gender } \\
\hline Male & $111(70)$ & $91(82)$ & $20(18)$ & $18(16)$ & $93(84)$ \\
\hline Female & $47 \quad(30)$ & 43 (91.5) & $4 \quad(8.5)$ & $13(28)$ & $34(72)$ \\
\hline \multicolumn{6}{|l|}{ Age lyrs) } \\
\hline$\leq 35$ & $63 \quad(40)$ & 52 (82.5) & $11(17.5)$ & $13(21)$ & $50(79)$ \\
\hline $36-49$ & 79 (50) & 70 (89) & $9(11)$ & $16(20)$ & $63(80)$ \\
\hline$\geq 50$ & $16(10)$ & $12(75)$ & $4 \quad(25)$ & $2(12.5)$ & $14(87.5)$ \\
\hline \multicolumn{6}{|l|}{ Education } \\
\hline USA & 20 (13) & $18(90)$ & $2(10)$ & $4 \quad(20)$ & $16(80)$ \\
\hline Western Europe & $9 \quad(6)$ & $7 \quad(78)$ & $2(22)$ & $2 \quad(22)$ & $7 \quad(78)$ \\
\hline Eastern Europe & 27 (17) & $21(78)$ & $6 \quad(22)$ & $6 \quad(22)$ & 21 (78) \\
\hline Middle East & $70 \quad(44)$ & $61(87)$ & $9(13)$ & $17(24)$ & $53(76)$ \\
\hline Asia & 32 (20) & 27 (84) & $5(16)$ & $216)$ & 30 (94) \\
\hline \multicolumn{6}{|l|}{ Specialty } \\
\hline GP & 99 (63) & $86(87)$ & $13(13)$ & $24(24)$ & 75 (76) \\
\hline Prosthodontics & 31 (20) & $26(84)$ & $5 \quad(16)$ & $5 \quad(16)$ & $26 \quad(84)$ \\
\hline Other Specialists & 28 (17) & $22(79)$ & $6 \quad(21)$ & 2 (7) & 26 (93) \\
\hline \multicolumn{6}{|l|}{ Workplace } \\
\hline Government & 125 (79) & 105 (84) & $20(16)$ & $22(18)$ & 103 (82) \\
\hline Private & 33 (21) & 29 (88) & $4 \quad(12)$ & $9 \quad$ (27) & $24 \quad$ (73) \\
\hline \multicolumn{6}{|l|}{ Area of Practice } \\
\hline Suburban & $51 \quad(32)$ & $46(90)$ & $5 \quad(10)$ & $6 \quad(12)$ & 45 (88) \\
\hline Urban & 107 (68) & $88(82)$ & 19 (18) & $25(23)$ & 82 (77) \\
\hline
\end{tabular}


gam as the restoration of choice for large cavities involving three surfaces. Dentists who chose to place an indirect restoration could possibly have been trying to prevent future tooth fracture. ${ }^{11}$

In a previous study carried out in the Netherlands, dental school teachers considered teeth with MOD amalgam restorations to have a higher fracture risk than those with resin composite restorations and, therefore, preferred to restore them with crowns. ${ }^{32}$ Our results showed that there was no difference in dentists' inclination to place indirect restorations when faced with failed amalgam or resin composite restorations, but that there was a clear preference to place an indirect restoration if cuspal fracture had occurred. This suggests that dentists in our study consider size of restoration to be a more important consideration than material strength in managing outcomes. This is supported by a previous study that found no significant difference in the prevalence of cuspal fracture in teeth restored with amalgam or resin composite. ${ }^{33}$ It has been shown that teeth with large amalgam restorations replacing one or two cusps were more likely to receive extensive and/or catastrophic treatment lendodontic treatment or extraction) in the future than teeth with crowns. $^{34,35}$ Our results support these findings, with the majority of participants choosing to place an indirect restoration for re-treatment of large amalgam or resin composite restorations when it is associated with cuspal fracture. On the other hand, some authors propose that extensive amalgam restorations (but not resin composite resin restorations) can be used as an appropriate alternative to crowns. ${ }^{36}$

Restorative treatment decisions have been found to be influenced by a number of dentists' characteristics such as gender, year and university of undergraduate education and type of practice. ${ }^{37,38}$ Recently it was shown that residents enrolled in postgraduate educational programs that focus on imparting clinical/technical skills are more interventive in their treatment decisions that those in more conventional academically-based programs. ${ }^{39}$ In general, our results indicate that the tendency to place indirect restorations is associated with increased dentist's age, being a male dentist, working in government sector and being a specialist other than a prosthodontist. Previous studies have found that dentists practicing for less than 10 years are more conservative,,$^{40}$ and private practitioners provide more fixed prosthodontic therapy than dentists employed in the dental public health service. . $^{14,20}$

Our findings support the general view that a variety of dentist, patient and treatment system factors contribute to the variability in decision making that is known to exist. Since differences in clinical decision making affect the cost-effectiveness and cost-benefit of oral healthcare, with impacts both at the individual patient, as well as at the population levels, research in this important area needs to continue.

\section{CONCLUSIONS}

In general, there was lack of agreement among dentists regarding re-treatment of failed posterior restorations. The lack of agreement appears to be due mainly to educational background, experience and workplace-related factors. The tendency towards cuspal coverage restorations in cases of a fractured cusp suggests that dentists may be concerned about poor retention and/or the risk of future fracture of compromised remaining tooth structure. The results suggest that the dental profession needs clearer guidelines to inform more effective and efficient decision making.

\section{REFERENCES}

1. Pink FE, Minden NJ, Simmonds S. Decisions of practitioners regarding placement of amalgam and composite restorations in general practice settings. Oper Dent 1994;19:127-132.

2. Friedl KH, Hiller KA, Schmalz G. Placement and replacement of amalgam in Germany. Oper Dent 1995;20:34-38.

3. Mjör IA, Moorhead JE, Dahl JE. Reasons for replacement of restorations in permanent teeth in general dental practice. Int Dent J 2000;50:360-366.

4. Mjör IA, Shen C, Eliasson ST, Richter S. Placement and replacement of restorations in general dental practice in Iceland. Oper Dent 2002;27:117-123.

5. Elderton RJ. Clinical studies concerning re-restoration of teeth. Adv Dent Res 1990;4:4-9

6. Tveit AB, Espelid I. Class II amalgams: interobserver variations in replacement decisions and diagnosis of caries and crevices. Int Dent J 1992;42:12-18.

7. Narby B, Kronstrom M, Soderfeldt, B, Palmqvist S. Prosthodontics and the patient: What is oral rehabilitation need? Conceptual analysis of need and demand for prosthodontic treatment. Part 1: Conceptual analysis. Int J Prosthodont $2005 ; 18: 75-79$. 
8. Maupomé G, Sheiham A. Clinical decision-making in restorative dentistry. Content-analysis of diagnostic thinking processes and concurrent concepts used in an educational environment. Eur J Dent Educ 2000;4:143-152.

9. Braga SR, Vasconcelos BT, Macedo MR, Martins VR, Sobral MA. Reasons for placement and replacement of direct restorative materials in Brazil. Quintessence Int 2007;38:e18994

10. Heft MW, Gilbert GH, Dolan TA, Foerster U. Restoration fractures, cusp fractures and root fragments in a diverse sample of adults: 24-month incidence. J Am Dent Assoc 2000;131:1459-1464.

11. Bader JD, Shugars DA, Roberson TM. Using crowns to prevent tooth fracture. Community Dent Oral Epidemiol 1996;24:47-51.

12. Shugars DA, Hayden WJ Jr, Crall JJ, Scurria MS. Variation in the use of crowns and their alternatives. J Dent Educ 1997;61:22-28.

13. Kolker JL, Damiano PC, Jones MP, Dawson DV, Caplan DJ, Armstrong SR, Flach SD, Kuthy RA, Warren JJ. The timing of subsequent treatment for teeth restored with large amalgams and crowns: factors related to the need for subsequent treatment. J Dent Res 2004;83:854-858.

14. Omar R, Al-Kokani M, Abu Nassif L, Khan NB. Influence of dentist-related factors on the time spent on providing prosthodontic services among general dentists. Saudi Dent $J$ 2003;15:2-10.

15. Bader JD, Shugars DA. What do we know about how dentists make caries-related treatment decisions? Community Dent Oral Epidemiol 1997;25:97-103.

16. Marinho VC, Richards D, Niederman R. Variation, certainty, evidence, and change in dental education: employing evidence-based dentistry in dental education. J Dent Educ 2001;65:449-455

17. Brennan DS, Spencer AJ. Factors influencing choice of dental treatment by private general practitioners. Int $\mathrm{J} \mathrm{Be}$ hav Med 2002;9:94-110.

18. Mjör IA, Moorhead JE, Dahl JE. Selection of restorative materials in permanent teeth in general dental practice. Acta Odontologica Scandinavia 1999;57:257-262.

19. Kay EJ, Blinkhorn AS. A qualitative investigation of factors govering dentist's treatment philosophies. Brit Dent J 1996;180:171-176.

20. Kronström M, Palmqvist S, Soderfeldt B. Prosthodontic decision making among general dentists in Sweden. I: The choice between crown therapy and filling. Int $J$ Prosthod $1999 ; 12: 426-431$.
21. Söderfeldt B, Palmqvist $S$, Eriksson T, Kronström M, Carlsson GE. A questionnaire instrument to assess clinical decision-making in prosthodontics among general practitioners. Acta Odontol Scand 1996;54:314-319

22. Kronström M, Palmqvist S, Söderfeldt B, Eriksson T, Carlsson GE. Congruence between self-reported and actually provided prosthodontic services among Swedish dentists. Acta Odontol Scand 1999;57:9-15.

23. Helminen SE, Vehkalati M, Murtomaa H. Dentists' perception of their treatment practices versus documented evidence. Int Den J 2002;52:71-74.

24. Brennan DS, Spencer AJ. Longitudinal comparison of factors influencing choice of dental treatment by private general practitioners. Aust Dent J 2006;51:117-123.

25. Bader JD, Shugars DA. Incidence rates for complete cusp fracture. Community Dent Oral Epidemiol 2001;29:346-353.

26. McDaniel RJ, Davis RD, Murchison DF, Cohen RB. Causes of failure among cuspal-coverage amalgam restorations: clinical survey. J Am Dent Assoc 2000;131:173-177.

27. Maupomé G. Cumulative assessment of factors leading top restorative decisions in an educational environment. A graphical demonstration using an in vitro case. Oper Dent 2000;25:336-343.

28. Al-Ali Al-Ali K, Marghalani H, Al-Yahya A, Omar R. An assessment of endodontic re-treatment decision-making in an educational setting. Int Endodont $J$ 2005;38:470-476.

29. Knutsson K, Lysell L, Rohlin M. Dentsuts' judgement strategies on prophylactic removal of mandibular third molars. J Dent Res 2000;79:1989-1995.

30. Omar R, Abu Nassif L, Al-Kokani M, Khan N. Factors influencing prosthodontic decision-making among general dentists. Saudi Dent J 2003;15:62-71.

31. Heinikainen M, Vehkalahti M, Murtomaa H. Re-treatment decisions for failed posterior fillings by Finnish general practitioners. Community Dent Health 2002;19:98-103.

32. Witter DJ, Kreulen CM, Creugers NH. Fracture risk judgment and crown indication by teachers in a dental school: a pilot study. Int J Prosthodont 2005;18:161-162.

33. Wahl MJ, Schmitt MM, Overton DA, Gordon MK. Prevalence of cusp fractures in teeth restored with amalgam and with resin-based composite. J Am Dent Assoc 2004;135:11271132.

34. Kolker JL, Damiano PC, Caplan DJ, Armstrong SR, Dawson DV, Jones MP, Flach SD, Warren JJ, Kuthy RA. Teeth with large amalgam restorations and crowns: factors affecting the receipt of subsequent treatment after 10 years. $J$ Am Dent Assoc 2005;136:738-748.

35. Martin JA, Bader JD. Five-year treatment outcomes for teeth with large amalgams and crowns. Oper Dent 1997;22:72-78. 
36. Van Nieuwenhuysen JP, D'Hoore W, Carvalho J, Qvist V. Long-term evaluation of extensive restorations in permanent teeth. J Dent 2003;31:395-405.

37. el-Mowafy OM, Lewis DW. Restorative decision making by Ontario dentists. J Can Dent Assoc 1994;60:305-310.

38. Brennan DS, Spencer AJ. The role of dentist, practice and patient factors in the provision of dental services. Соттиnity Dent Oral Epidemiol 2005;33:181-195.

39. Akeel R. Influence of educational background on stated retreatment choices for sub-optimal fixed prosthodontic conditions. J Prosthodont 2008;17:156-164.

40. Traebert J, Marcenes W, Kreutz JV, Oliveira R, Piazza CH, Peres MA. Brazilian dentists' restorative treatment decisions. Oral Health Prev Dent 2005;3:53-60. 